\title{
Cutaneous metastasis of a breast cancer diagnosed 13 years before*
}

\author{
Maraya de Jesus Semblano Bittencourt ${ }^{1}$ \\ Bianca Angelina Macêdo do Nascimento ${ }^{1}$ \\ Amanda Magno de Parijós ${ }^{2}$
}

\author{
Alessandra Haber Carvalho ${ }^{1}$ \\ Lívia Karlla Marinho Freitas ${ }^{1}$
}

DOI: http:/ / dx.doi.org/10.1590/abd1806-4841.20153842

\begin{abstract}
A bstract: Metastasis is defined as a neoplastic lesion originating from another primary tumor, with which it is no longer in contact. Cutaneous metastases result from lymphatic embolization, hematogenous or contiguous dissemination or also direct implantation during surgical procedures. In women, the tumor most likely to metastasize to skin is breast cancer, which may manifest as papulonodular neoplastic lesions. We report the case of a 66 years old female patient, presenting papulonodular lesions13 years after the initial treatment with surgery and chemotherapy for a cancer of the left breast.
\end{abstract}

Keywords: Breast neoplasms; Histology; Neoplasm metastasis

\section{INIRODUCTION}

Metastasis is defined as a neoplastic lesion originating from another primary tumor, with which it is no longer in contact. Cutaneous metastases occur in 0.7 to $10.4 \%$ of all patients diagnosed with cancer although they represent only $2 \%$ of all skin tumors. ${ }^{1}$ They can be the first signof a clinically silent neoplasm or even an indication of tumoral relapse. ${ }^{2}$ The interval between tumor diagnosis and the appearance of subsequent metastases is variable, but in general, they occur in the first three years after diagnosis. ${ }^{3,4}$

\section{CASE REPORT}

A sixty-six year-old female patient reported the appearance of multiple asymptomatic cutaneous nodules 8 months prior to the consultation, associated to persistent dry cough and loss of $5 \mathrm{~kg}$ in this period. She had a past history of partial mastectomy on the left breast followed by chemotherapy 13 years before, on account of a previous diagnosis of breast neoplasm. On dermatologic examination the patient presented painless, hardened, skin-colored nodules, fixed to underlying tissues, measuring 2 to $3 \mathrm{~cm}$ and spread over the cervical region, back and upper limbs (Figure 1).

Anatomopathological examination of the skin biopsy, performed on the back, showed the dermis infiltrated by an atypical neoplasm formed by epithelial cells with abundant cytoplasm, hyperchromatic pleomorphic nuclei and distinct nucleoli, arranged in columns and glandular-like structures in the midst of desmoplastic collagen, without associated inflammatory reaction (Figure 2). Results were consistent with moderately differentiated adenocarcinoma and the sample was sent for immunohistochemical examination. Immunohistochemistry was positive for cytokeratin 7, carcinoembryonic antigen (CEA), estrogen receptor (ER) and GCDFP-15; and negative for cytokeratin 20, thyroid-lung transcription factor (TTF-1), intestinal transcription factor (CDX2), S100 protein and mammaglobin, indicating the breast as the primary site of neoplasm. 

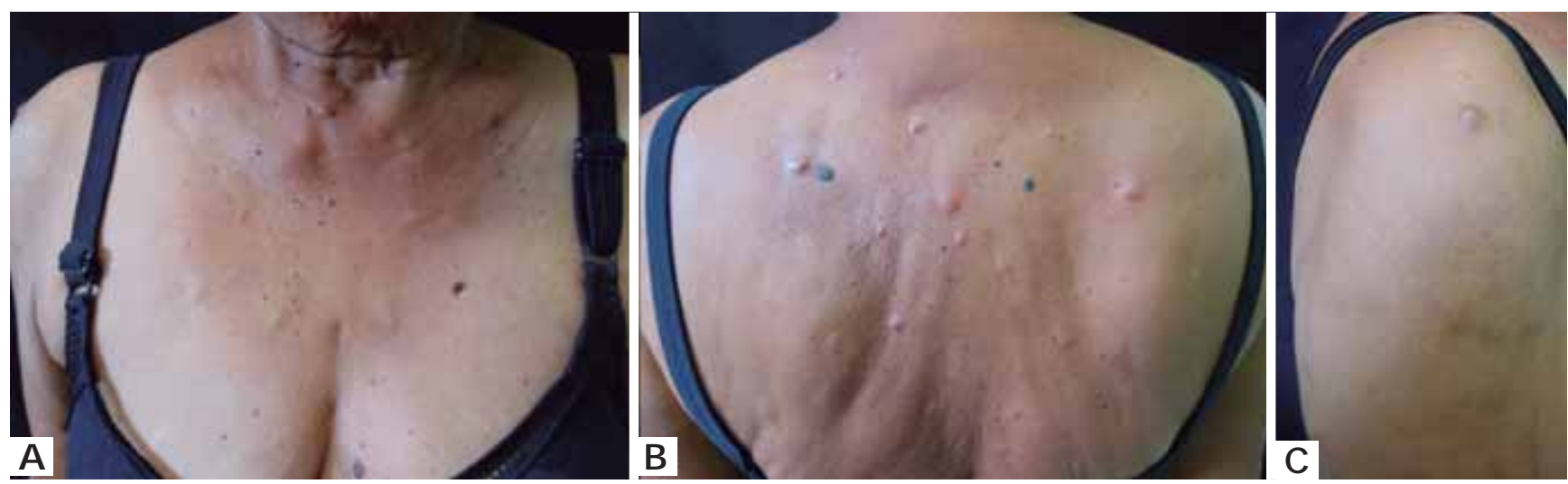

Figure 1: A, B e C: Multiple painless, hardened, skin-colored nodules measuring 2-3 $\mathrm{cm}$ in average and spread to the cervical region, anterior e posterior chest walls and upper limbs
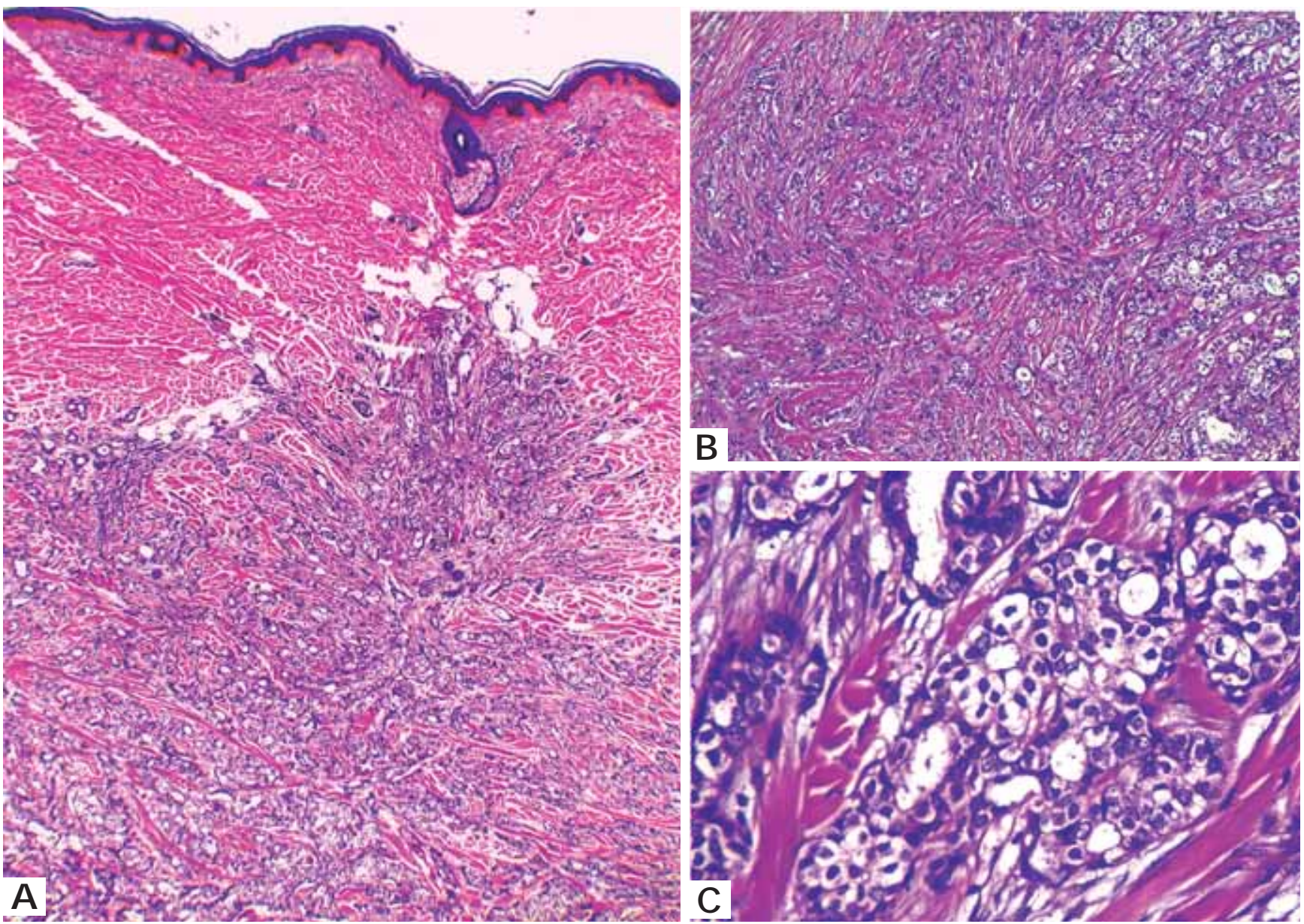

FIgURE 2: Anatomopathological exam of dorsal skin biopsy, stained by hematoxylin and eosin.

A: dermis infiltrated by an atypical neoplasm formed by epithelial cells, with abundant cytoplasm, pleomorphic and hyperchromatic nuclei and distinct nucleoli, disposed in columns and glandular-like structures, amid desmoplastic collagen without associated inflammation (HEx10).

B: Detail of the proliferation disposition in stromal fibrosis, as columns and glandular-like structures (HE x 40)

C: Detail of the neoplastic proliferation highlighting the glandular aspects (HE x 40).

Results were consistent with moderately differentiated adenocarcinoma and the sample was sent to immunohistochemistry examination 
Laboratory exams evidenced elevation of CEA serum levels: $8.8 \mathrm{ng} / \mathrm{ml}$ (normal up to $2.5 \mathrm{ng} / \mathrm{ml}$ ) and CA125: $246 \mathrm{U} / \mathrm{ml}$ (normal < $35 \mathrm{U} / \mathrm{ml}$ ). Alfa fetoprotein, CA19.9 and other tests were normal. Computerized tomography (CT scan) of the thorax showed interstitial infiltration and nodules, pleural effusion and enlarged lymph nodes (Figure 3). Abdominal ultrasound and cranial CT scan were unaltered

\section{DISCUSSION}

The skin does not appear to be a preferred target organ for the development of metastases. Usually, when the skin is affected by metastases, other organs have already been involved marking the former as a sign of poor prognosis. ${ }^{5}$ Cutaneous metastases result from lymphatic embolization, hematogenous or contiguous dissemination or also direct implantation during surgical procedures. ${ }^{4,5}$ Breast carcinoma is the second most common cancer in women and the most common tumor leading to the appearance of skin metastasis. ${ }^{6}$ In the largest case series already published, cutaneous involvement was observed in $23.9 \%$ of all patients. ${ }^{7}$

Cutaneous metastases arising from breast cancer may present varied morphology. The most common presentation is in the form of nodules, located on the thoracic wall and abdomen, although they can also affect limbs and the head-and-neck region. These

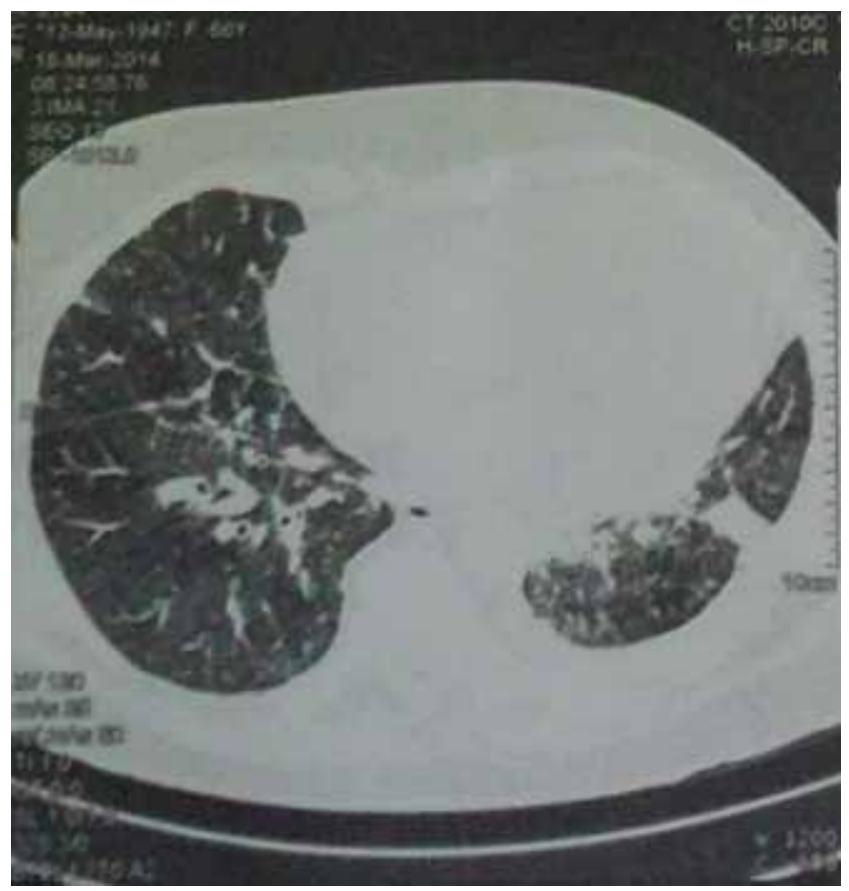

Figure 3: Thoracic CT scan showing the presence of pulmonary nodules, lymphadenomegaly and pleura effusion nodules vary in size from 1 to $3 \mathrm{~cm}$ and appear as hardened lesions, either single or multiple, located on dermis and subcutaneous tissue, as observed on the patient in question.

Generally, their color is similar to that of normal adjacent skin and they are asymptomatic. On occasion, lesions may erode and ulcerate secondary to the tumoral mass pressure on cutaneous surface. The anterior thoracic wall is the area most affected by cutaneous metastases secondary to breast cancer, as described in this report. ${ }^{4}$ Other clinical presentations include erysipeloid infiltration, sclerodermiform, inflammatory carcinoma, en cuirasse, telangiectatic, neoplastic alopecia and palpebral nodules.

The most frequent histopathologic pattern in cutaneous metastases is the enlarged nodule, located on the deeper dermis, adjacent to or insideits intersection with the subcutaneous tissue. Essentially, it presents as solid aggregates of neoplastic cells surrounded by fibrosis, with tumoral cells typically disposed in glandular-like structures or linearly between groups of collagen fibers in a single file pattern. Inflammatory reaction is often minimal or even non-existent. Most metastatic carcinomas express cytokeratins (CK) 7 and 19 , estrogen and progesterone receptors, mammaglobin, GCDFP-15, CEA and E-cadherin, even though theymay be negative for CK20, CK5/6, CD10 and TTF-1. ${ }^{6}$

The age range with the highest incidence of cutaneous metastases is that between 50 and 70 years old. The interval between the primary tumor diagnosis and the subsequent metastasis is variable, but, in general, it occurs in the first three years after the initial diagnosis. ${ }^{3,4}$ In patients with primary breast cancer, cutaneous metastases usually appear later than metastases in other organs. ${ }^{8}$

There is an association between estrogen receptors and time to metastasis. Primary tumors with positive estrogen receptors (ER) have significantly longer disease-free periods than ER negative neoplasms. ${ }^{3}$ The immunohistochemistry results for this patient's primary tumor are unknown, but the skin metastasis was ER positive, which might have contributed to the late appearance of the lesions.

Besides cutaneous metastases, our patient's lung was also affected by the tumor. Lung is often the first site of tumor relapse after surgery. The most frequently seen pattern is that of pleural metastasis, follow by hilar and/or mediastinal lesions and pulmonary nodules, as observed in this case. It is estimated that $60-74 \%$ of patients that die of breast cancer, also had pulmonary metastases, with the lung as the sole site of metastases in $21 \%$ of cases. ${ }^{9}$

Cutaneous metastases can be the first clinical manifestation of an unknown intern malignant tu- 
mor or the first sign of metastasis from a seemingly treated cancer. The appearance of these lesions indicates generalized metastatic disease, implying in poor prognosis. Patients often survive for a short period of time, depending on the type of carcinoma. Therefore, although rare in dermatologists' clinical practice, cutaneous metastases are clinically important, because their immediate detection may contribute to reduce associated morbidities and mortality.

\section{REFERENCES}

1. De Giorgi V, Grazzini M, Alfaioli B, Savarese I, Corciova SA, Guerriero G, et al. Cutaneous manifestations of breast carcinoma. Dermatol Ther. 2010;23:581-9.

2. Virmani NC, Sharma YK, Panicker NK, Dash KN, Patvekar MA, Deo KS. Zosteriform skin metastases: clue to an undiagnosed breast cancer. Indian J Dermatol. 2011;56:726-7.

3. Hwang SK, Chen Z, Sun Q, Pan R, Pang MH. Cutaneous metastasis of breast cancer previously diagnosed 25 years ago. Chin Med J (Engl). 2014;127:1000.

4. Oliveira GM, Zachetti DB, Barros HR, Tiengo A, Romiti N. Breast carcinoma en Cuirasse--case report. An Bras Dermatol. 2013;88:608-10.

5. Sittart JA, Senise M. Cutaneous metastasis from internal carcinomas: a review of 45 years. An Bras Dermatol. 2013;88:541-4.

6. Alcaraz I, Cerroni L, Rütten A, Kutzner H, Requena L. Cutaneous metastases from internal malignancies: a clinicopathologic and immunohistochemical review. Am J Dermatopathol. 2012;34:347-93

7. Lookingbill DP, Spangler N, Helm KF. Cutaneous metastases in patients with metastatic carcinoma: a retrospective study of 4020 patients. J Am Acad Dermatol. 1993;29:228-36.

8. van den Hurk CJ, Eckel R, van de Poll-Franse LV, Coebergh JW, Nortier JW, Hölzel $\mathrm{D}$, et al. Unfavourable pattern of metastases in M0 breast cancer patients during 1978-2008: a population-based analysis of the Munich Cancer Registry. Breast Cancer Res Treat. 2011;128:795-805.

9. Kreisman H, Wolkove N, Finkelstein HS, Cohen C, Margolese R, Frank H. Breast cancer and thoracic metastases: review of 119 patients. Thorax. 1983;38:175-9.
M AILING ADDRESS:

$M$ araya de Jesus Semblano Bittencourt

A venida G eneralíssimo D eodoro, 91

U marizal,

66055-240 - Belém - PA

Brazil

E-mail: marayabittencourt@hotmail.com

H ow to cite this article: Bittencourt MJS, Carvalho AH, Nascimento BAM, Freitas LKM, Parijós AM. Cutaneous metastasis of a breast cancer diagnosed 13 years before. An Bras Dermatol. 2015;90 (3 Suppl 1):S134-7. 